\title{
Studies of Chemical Fixation Effects in Human Cell Lines Using Raman Microspectroscopy
}

\author{
Aidan Meade \\ Technological University Dublin, aidan.meade@tudublin.ie \\ Colin Clarke \\ Technological University Dublin, Colin.Clarke@tudublin.ie \\ Florence Draux \\ Universite de Reims Champagne-Ardenne
}

See next page for additional authors

Follow this and additional works at: https://arrow.tudublin.ie/scschphyart

Part of the Physics Commons

\section{Recommended Citation \\ Meade, A.D. et al (2010) Studies of chemical fixation effects in human cell lines using Raman microspectroscopy. Analytical and Bioanalytical Chemistry Vol. 396, Number 5, pp. 1781-1791. doi:10.1007/s00216-009-3411-7}

This Article is brought to you for free and open access by the School of Physics \& Clinical \& Optometric Science at ARROW@TU Dublin. It has been accepted for inclusion in Articles by an authorized administrator of ARROW@TU Dublin. For more information, please contact arrow.admin@tudublin.ie, aisling.coyne@tudublin.ie, gerard.connolly@tudublin.ie.

Funder: Enterprise Ireland International Collaboration Award (and French equivalent PAI Ulysses Programme. Collaboration also conducted under the DAISM (Diagnostic Application of Synchroton Infrared Microscopy) Special Support Activity Funded by EU Contract no. 005326 under the European Framework 6 


\section{Authors}

Aidan Meade, Colin Clarke, Florence Draux, Ganesh Sockalingum, Michel Manfait, Fiona Lyng, and Hugh Byrne 


\title{
Studies of chemical fixation effects in human cell lines using Raman microspectroscopy
}

\author{
Aidan D. Meade ${ }^{1,2^{*}}$, Colin Clarke ${ }^{2}$, Florence Draux ${ }^{3}$, Ganesh D. Sockalingum $^{3}$, \\ Michel Manfait ${ }^{3}$, Fiona M. Lyng ${ }^{2}$, Hugh J. Byrne ${ }^{4}$
}

1. School of Physics, Dublin Institute of Technology, Kevin Street, Dublin 8, Ireland.

2. Radiation and Environmental Science Centre, Focas Research Institute, Dublin Institute of Technology, Camden Row, Dublin 8, Ireland.

3. Unité MéDIAN, Université de Reims Champagne-Ardenne, CNRS UMR 6237, 51 Rue Cognac-Jay, 51096 Reims, France.

4. Focas Research Institute, Dublin Institute of Technology, Camden Row, Dublin 8, Ireland.

*Author to whom correspondence should be addressed: aidan.meade@ dit.ie

\section{Abstract}

The in-vitro study of cellular species using Raman spectroscopy has proven a powerful noninvasive modality for the analysis of cell constituents and processes. This work uses micro-Raman spectroscopy to study the chemical fixation mechanism in three human cell lines (normal skin, normal bronchial epithelium, and lung adenocarcinoma) employing fixatives that preferentially preserve proteins (formalin), and nucleic acids (Carnoy's fixative and Methanol-Acetic Acid). Spectral differences between the mean live cell spectra and fixed cell spectra together with principal components analysis (PCA), and clustering techniques were used to analyse and interpret the spectral changes. The results indicate that fixation in formalin produces spectral content that is closest to that in the live cell and by extension best preserves the cellular integrity. Nucleic acid degradation, protein denaturation, and lipid leaching were observed with all fixatives and for all cell lines, but to varying degrees. The results presented here suggest that the mechanism of fixation for short fixation times is complex and dependent on both the cell line and fixative employed. Moreover, important spectral changes occur with all fixatives that have consequences for the interpretation of biochemical processes within fixed cells. The study further demonstrates the potential of vibrational spectroscopy in the characterization of complex biochemical processes in cells at a molecular level. 
Keywords: micro-Raman spectroscopy, chemical fixation mechanisms, cell

culture, Formalin, Carnoy's Fixative, Methanol-Acetic Acid, PCA, HCA, k-means

clustering.

\section{Introduction}

The techniques of vibrational spectroscopy (Raman and/or Fourier-Transform Infrared (FTIR) spectroscopy) have undergone significant advances in the last decade. The incorporation of microscope attachments to spectrometers has provided the means to acquire spatially resolved molecular fingerprints of cells and of tissue samples [1,2]. While FTIR microspectroscopy requires that samples be desiccated to remove the contaminating effects of water, Raman spectroscopy provides a platform for the acquisition of such information in living biological samples [3-5], although alternative experiments may require the preservation, of the sample in order to perform parallel studies such as confocal microscopy or immunohistochemistry [2]. The effects of chemical fixation are not fully characterized in the literature. While notable attempts have been made to analyse these effects in cells using vibrational spectroscopy [6-10], to our knowledge no spectroscopic evaluation of spectral variation between fixed and live cells has been performed to date.

Chemical fixation was initially developed in the latter part of the $19^{\text {th }}$ century as a means of preserving tissue for microscopic observation, although fixation of tissues has been conducted for millennia [11,12]. In the post genomic era, issues surrounding the molecular integrity of biological samples post-chemical fixation have come under scrutiny [12-16], particularly in specimens preserved in tissuebanks [16]. The most common fixatives are aldehydes (formaldehyde and glutaraldehyde), alcohols (methanol, ethanol), ketones (acetone), and acids (tannic acid, picric acid, etc.). When used individually these fixatives induce unwanted effects in the chemistry of the biological sample.

For example, formaldehyde (in the form of neutral buffered formalin (NBF)) breaks hydrogen bonds within large intracellular molecules [12]. It causes the denaturation of intracellular proteins through the formation of cross-links between amine residues [6,12,17], generating overall shrinkage of the sample volume [12], and resulting in the loss of integrity of the quaternary, tertiary and possibly secondary conformation of proteins [18]. It is quite well known that formalin fixes proteins in a time-dependent reaction, which appears to have little effect within two hours in tissues, but is complete at 24 hours [11]. In addition it reduces the binding specificity of antigens in immunohistochemical staining [19] when applied to the biological specimen for long periods of time and causes a reduction in DNA solubility [12], cleaving the backbone of DNA and RNA [12-14,16] in a slow hydrolysis reaction. It is also known that RNA quality in formalin fixed tissue is quite poor. Other studies $[8,11,12,14,18,20]$ have demonstrated that formalin-fixation unstacks DNA bases in adenine-thymine rich regions [12]. It can also form hydroxyl-methyl groups with nucleic acid bases and hydrolyze N- 
glycosidic bonds in the base residues to form free purine and pyrimidine groups [12]. There is also evidence that it washes out lipid [15].

Fixation in acetone causes the dehydration of biological specimens, which may render them fragile, and solubilises lipid [18]. Alcohols such as methanol and ethanol have been shown to preserve nucleic acids, but have strongly denaturing effects on protein [18]. Both are employed as mixtures of fixatives in an attempt to overcome the shortcomings of each of the individual fixatives. Ethanol is the main constituent found in Carnoy's fixative, while methanol may be employed as Methacarn (a mixture of chloroform with methanol and glacial acetic acid) or as a methanol-glacial acetic acid mixture (Meth-Ac). Carnoy's fixative preserves nucleic acids, although fragment size retained with either this fixative or Meth-Ac is different [16].

Previous studies of the effect of chemical fixatives on biological specimens with vibrational spectroscopy have concentrated on evaluating the effect of formalin fixation and paraffin preservation on spectral features of potential diagnostic interest in tissue [7,8,21-23] and cells, both in a qualitative and quantitative fashion. These studies have concluded that the major effect of formalin fixation is to the lipid and protein structures and content within the cell $[6,9,10]$.

In this work we report the results of experiments comparing Raman spectra from various cell lines in their live form to those from cells fixed using neutral buffered formalin, Carnoy's fixative, and a methanol-glacial acetic acid mixture. The cell lines used were a normal human keratinocyte cell line (HaCaT [24,25]), a normal human bronchial cell line (BEAS2B) and a human adenocarcinoma cell line (A549). The results suggest that that formalin preserves the spectral content closest to that observed in the live state.

\section{Materials and Methods}

\section{Cell Culture and Fixation}

HaCaT and A549 cells were cultured to 80\% confluence in DMEM-F12 (Gibco, Irvine, UK) supplemented with $10 \%$ Foetal Bovine solution (Gibco, Irvine, UK) and $1 \%$ pen-strep (Gibco). BEAS2B cells were cultured to similar confluency in RPMI-1540 (Gibco, Irvine, UK) with the same supplements. All cells were within 10-50 passages of the primary cell line.

Cells were cultured on quartz substrates, which had been previously coated with a $2 \% \mathrm{w} / \mathrm{v}$ gelatin-water solution, whose suitability for Raman spectral analysis has been shown previously (and details of its preparation are available elsewhere) [25]. All samples were prepared in triplicate. Approximately $1 \times 10^{6}$ cells were added to each substrate and incubated for two hours to affect initial attachment. Subsequently the cells were incubated in $3 \mathrm{ml}$ complete medium for 24 hours at $37^{\circ} \mathrm{C}$ before analysis. 
Samples for analysis in live form were maintained in growth medium until the time of analysis. The growth medium was aspirated from all samples prior to fixation and they were washed several times in distilled water $\left(\mathrm{dH}_{2} \mathrm{O}\right)$ and stored in $\mathrm{dH}_{2} \mathrm{O}$ after fixation. All samples were analysed within 6-8 hours of fixation to minimise any reversal of the fixation process which has previously been seen to occur over weeks of washing with water [26]. Fixation occurred at room temperature and all fixatives were prepared immediately before fixation began. Samples for formalin fixation were fixed in neutral buffered formalin (Gibco, Irvine, UK) for 10 mins. Samples for fixation in Carnoy's fixative (60\% absolute ethanol, 30\% chloroform, 10\% glacial acetic acid) and methanol-acetic acid (Meth-Ac; 3:1 mixture) were incubated in the fixative for 5 minutes. After the first fixation step, samples for Meth-Ac fixation were washed briefly in fresh fixative and then incubated in more fresh fixative for a further 10 minutes [27].

\section{Spectral Acquisition and Preprocessing}

Spectra were acquired on a Horiba Jobin-Yvon SAS (Villeneuve d'Ascq, France) LabRam instrument equipped with an excitation laser operating at $785 \mathrm{~nm}$ delivering a power of approximately $70 \mathrm{~mW}$ at the sample. Spectra were acquired in the range from $620 \mathrm{~cm}^{-1}$ to $1780 \mathrm{~cm}^{-1}$ using a slit width of $100 \mu \mathrm{m}$ and a confocal hole diameter of $1000 \mu \mathrm{m}$. A water immersion objective with a magnification of $\times 100$ was used to focus the excitation laser onto the sample, giving a lateral resolution of approximately $1 \mu \mathrm{m}$ and a vertical resolution of approximately $2 \mu \mathrm{m}$. The instrument was calibrated to the $520.7 \mathrm{~cm}^{-1}$ line of silicon, and spectra were subsequently acquired of a neon lamp source (without laser excitation), cyclohexane and 1,4 Bis (2-methylstyryl) benzene (with laser excitation) to verify the calibration of the Raman collection optics over the spectral range of acquisition. Spectra of the CCD dark-current background (without laser excitation), the CCD output as a result of illumination with a tungsten-halogen light source (also without laser excitation) were acquired. Finally, spectra of the substrate (gelatin coated quartz) were recorded. All of these spectra were acquired in triplicate prior to spectral measurement. Samples were placed in glass-bottomed petri dishes and immersed in physiological saline throughout the measurement. All measurements on a live sample were conducted for a maximum period of 1-hour.

All subsequent spectral processing and analysis was performed using Matlab 7.2 (The MathWorks Inc., USA). Outlying spectra were removed using Grubb's test [28] of Mahalanobis distances between the scores of the first three principal components of each spectral dataset. Spectra were corrected for the instrument CCD output (using an acquired spectrum from a blackbody source), and the quartz substrate (which includes both contributions from the quartz background and the water from the physiological saline), and the resulting spectrum was fitted with a fifth order polynomial that was subtracted to remove any residual spectral baseline. 


\section{Multivariate Analysis}

As part of the analysis of the spectral datasets it was necessary to employ multivariate methods. Principal components analysis (PCA) and cluster analysis (CA) were the methods employed here. PCA allows the reduction of a matrix of spectral data in which each object (spectrum) is a measurement with a large number of variables (wavenumber) [29] to a smaller number of variables (principal components (PC's)) which describe the majority of the variance in the complete spectral dataset.

CA techniques allow the combination of multivariate measurements into groups, and can analyse group membership in a supervised or non-supervised fashion [30]. These techniques are utilised here to provide quantitative measurements of the dissimilarity between spectra of cells in the live versus fixed forms using clustering of first derivative spectra. In this work this technique was used to establish the location of an accurate centroid for each cluster. Cluster analyses were performed for each cell line separately, and also separately for spectral regions incorporating the vibrations of nucleic acid, protein, lipid and carbohydrate within each cell line. Distances between the centroids of the live cell and fixed cell clusters were calculated for each cell line, fixative and spectral region. This allows the examination of the effect of each fixative on each cell line, and on each specific biochemical species.

\section{Results}

\section{Raman spectral features and Difference Spectra}

The mean Raman spectra of live A549, BEAS2B and HaCaT cells are shown in figure 1. Peak assignments used to interpret the Raman spectra of these cells are taken from multiple peer-reviewed sources [25,31-36]. The spectra of each of the cell lines exhibit strong Amide I (centred at $1667 \mathrm{~cm}^{-1}$ ) and Amide III (1305 to $1270 \mathrm{~cm}^{-1}$ ) vibrations, but weak Amide II vibrations $\left(1565 \mathrm{~cm}^{-1}\right)$. Lipid $\mathrm{CH}$ deformations (from 1480 to $1420 \mathrm{~cm}^{-1}$ ) are particularly intense, although some overlap with $\mathrm{CH}_{2}$ and $\mathrm{CH}_{3}$ deformation vibrations in protein also occurs in this region. Strong vibrations are also evident in regions assigned to purine and pyrimidine residues $\left(788-677 \mathrm{~cm}^{-1}\right)$, and aromatics such as phenylalanine ringbreathing $\left(1004 \mathrm{~cm}^{-1}\right)$. Phosphate stretching modes of DNA and RNA (1095-1060 $\left.\mathrm{cm}^{-1}\right)$, and their backbone $\left(928-788 \mathrm{~cm}^{-1}\right)$ are also particularly strong.

The spectra of each of the fixatives are shown in figure 2. As a primary examination of the fixation effects in each cell line the difference spectra between the mean live cell spectra (which act as a reference control for each cell line) and mean cell fixed spectra, for each fixative in each cell line, were computed and are shown in figure 3. Spectral vibrations throughout the Raman spectrum have their origin in various molecular species (nucleic acid, protein, lipid) and overlap strongly. The approach adopted here is to firstly identify clear and strong sources of variability that are apparent in the results, and then to identify other sources of 
variability that support the adjustment seen to this moiety at other points in the spectrum. Thus the presence of variability in a given moiety (which is overlapped by features from another molecular vibration) is only noted where there are similar adjustments to other vibrations of that moiety.

Firstly, a visual examination of the difference spectra in each case demonstrates that they do not contain features associated with the chemical fixatives that are shown in figure 2. It is also apparent from the intensity of the difference spectra that the level of fixation effect seen spectrally is cell line and fixative dependent. In the A549 difference spectra (figure 3(a)), decreases in the vibrational intensity of DNA (1095 $\mathrm{cm}^{-1}$ to $\left.1060 \mathrm{~cm}^{-1} ; 789-788 \mathrm{~cm}^{-1}\right)$ and RNA $\left(812-811 \mathrm{~cm}^{-1}\right)$ phosphodiester stretches are evident after treatment with each of the fixatives. The vibrations of the DNA B $\left(833 \mathrm{~cm}^{-1}\right)$ and $C\left(870 \mathrm{~cm}^{-1}\right)$ forms and that of the DNA backbone at $929-928 \mathrm{~cm}^{-1}$ are decreased by all fixatives. Osidic bond vibrations (C-O at 1160-1100 $\mathrm{cm}^{-1}$ ) also decrease. In addition the vibrational intensities of nucleic acid bases (guanine and adenine $\left(1487-1486 \mathrm{~cm}^{-1} ; 682-681 \mathrm{~cm}^{-1} ; 670-677\right.$ $\left.\mathrm{cm}^{-1}\right)$, thymine $\left(788-782 \mathrm{~cm}^{-1} ; 730-729 \mathrm{~cm}^{-1}\right)$ and cytosine ring breathing (788$782 \mathrm{~cm}^{-1}$, where this overlaps with the same mode in uracil)) are decreased as a result of fixation. The ring breathing modes of these moieties are also shifted slightly (T ring breathing shifts from $750 \mathrm{~cm}^{-1}$ to 752,743 and $753 \mathrm{~cm}^{-1}$; A ring breathing shifts from $729 \mathrm{~cm}^{-1}$ to 727,730 and $733 \mathrm{~cm}^{-1}$; $\mathrm{G}$ ring breathing shifts from $681 \mathrm{~cm}^{-1}$ to 688,690 and $691 \mathrm{~cm}^{-1}$; these occur in each case after treatment with Carnoy's fixative, formalin and Meth-Ac respectively). Other carbohydrate vibrations ( $v$ C-O of osidic and $v$ C-O-C of glycosidic bond from $937-930 \mathrm{~cm}^{-1}$ ) are also decreased.

In regions assigned to protein, there are decreases of the Amide I (1688-1655 $\mathrm{cm}^{-}$ $\left.{ }^{1}\right)$ and Amide III (1305-1220 $\left.\mathrm{cm}^{-1}\right)$ vibrational modes together with decreases in vibrations assigned to the deformation of $\mathrm{CH}$ bonds $\left(1451-1450 \mathrm{~cm}^{-1}, 1339-1305\right.$ $\left.\mathrm{cm}^{-1}, 1300 \mathrm{~cm}^{-1}\right)$. The peaks in the difference spectra are located in the region from $1668-1661 \mathrm{~cm}^{-1}$ in the Amide I band, with those in the Amide III region located in the region from 1300-1239 $\mathrm{cm}^{-1}$ suggesting that the fixative-dependent adjustments to the vibrations of protein are mainly to their random chain and $\alpha$ helical orientations. Other modes assigned to phenylalanine (1033-1031; 1005$\left.1001 \mathrm{~cm}^{-1}\right)$, tyrosine $\left(1177-1776 \mathrm{~cm}^{-1} ; 1168-1167 \mathrm{~cm}^{-1}\right)$ and tryptophan (1424$1422 \mathrm{~cm}^{-1} ; 761-760 \mathrm{~cm}^{-1}$ ) residues are also decreased. Slight shifts in the vibrational frequency of some modes of these moieties are also seen after treatment (phenylalanine ring breathing mode changes from $1004 \mathrm{~cm}^{-1}$ to 1001 , 1003 and $1006 \mathrm{~cm}^{-1}$; tryptophan ring breathing mode changes from 760 to 761 , 763 and $764 \mathrm{~cm}^{-1}$; tyrosine $\mathrm{CH}$ bending vibration changes from 1176 to 1175 , 1171 and $1172 \mathrm{~cm}^{-1}$; these occur in each case after treatment with Carnoy's fixative, formalin and Meth-Ac respectively). Overall, these effects suggest adjustments to the quaternary, tertiary and secondary conformation of protein [6].

Lipid vibrations in the region of $715-730 \mathrm{~cm}^{-1}\left(\mathrm{CH}_{2}\right.$ rocking vibrations [36]), 1300 $\mathrm{cm}^{-1}$ ( $\mathrm{CH}_{2}$ twist), from $1480 \mathrm{~cm}^{-1}$ to $1420 \mathrm{~cm}^{-1}$ (CH deformation) and in the 1740$1733 \mathrm{~cm}^{-1}(\mathrm{C}=\mathrm{O}$ stretch$)$ region are decreased in A549 cells after fixation, perhaps suggesting that fixation leaches lipid from within the cell, as noted elsewhere $[6,16]$ (It must be noted that the $\mathrm{CH}$ deformation region also has an overlap with the broad $\mathrm{CH}$ deformation vibrations in guanine, adenine, and protein at $1450 \mathrm{~cm}^{-}$ $\left.{ }^{1}\right)$. In addition, the $\mathrm{CH}_{3}$ symmetric bending vibration $\left(1405-1395 \mathrm{~cm}^{-1}\right)$ and $=\mathrm{C}-\mathrm{H}$ 
bending vibrations $\left(1284-1220 \mathrm{~cm}^{-1}\right)$ both decrease in intensity after fixation. This implies that, although lipid leaching may occur, an adjustment to the permeability of the cellular membrane as a result of fixation is also possible, as seen elsewhere $[20,37]$.

Very similar effects are seen in the difference spectra of BEAS2B (figure 3(b)) and $\mathrm{HaCaT}$ cells (figure 3(c)). However it is apparent from the intensity of the difference spectra that the level of fixation effect seen after treatment with any given fixative spectrally is cell line dependent. The effects on nucleic acid features are quite similar in both cell lines to those noted for A549 cells, although some important differences exist. The osidic $\left(\mathrm{C}-\mathrm{O}\right.$ at $\left.1160-1100 \mathrm{~cm}^{-1}\right)$ bond vibrations decrease slightly in intensity in BEAS2B cells after fixation in formalin and MethAc. Of note also is the presence of a peak at $774 \mathrm{~cm}^{-1}$ in the difference spectra of BEAS2B cells fixed in formalin and in HaCaT cells fixed in each of the three fixatives. This is attributable to ring vibrations in $\alpha$ and $\beta$-pyranose carbohydrates $\left(785-755 \mathrm{~cm}^{-1}\right)$ [36]. The effects of fixation on protein in HaCaT and BEAS2B cells are very similar to those seen in A549 cells, with decreases to the Amide I, Amide III, $\mathrm{CH}$ deformation and residue vibrations as a result of fixation by all fixatives. Peak shifts to certain protein residue vibrations in both cell lines were also seen to occur after treatment with all fixatives (phenylalanine ring breathing mode changes from $1004 \mathrm{~cm}^{-1}$ to approximately $993 \mathrm{~cm}^{-1}$ in each cell lines; tryptophan ring breathing mode changes from 760 to between 759 and $746 \mathrm{~cm}^{-1}$ ). In terms of changes to lipid spectral features, similar spectral adjustments are seen to those previously noted for A549 cells.

\section{Multivariate Analysis}

An interrogation of the mechanism of fixation in each fixative was performed by conducting separate PCA analyses on the spectra acquired from the live cells together with those from each of its fixed counterparts, for each of the cell lines. It is thus possible to determine the reason for the dissimilarity between the spectral datasets, and gain an insight into the mechanism by which fixation occurs, through examination of the principal component loadings [38]. The PCA loadings in principal component 1 through 3 are displayed in figures 4(a) through 4(c). Loadings on a given principal component describe the extent to which the variables in the analysis (wavenumbers) vary in the same (in the case of variables with positive values) or in the opposite direction (variables with negative values) to the PC [39]. High loadings are therefore interpreted as indicating variables which are of significant influence on the separation of the spectra from each cellular category. Given the overlapping nature of spectral features from different molecular species within various bands of the Raman spectrum of biological cells, caution has been adopted here in interpretation of single peaks within PC loadings. When variations in a single peak in the spectral loadings are seen, suggestive of variability in a certain chemical moiety, they are interpreted only where this variation is accompanied by variability in other modes of vibration of that moiety.

It is again notable that the PC loadings confirm that there is no latent contribution from the chemical fixatives themselves in the cell spectra since there is an absence of strong positive loadings in the PC's that could be associated with the chemical 
fixatives (see figure 2). In each of the cell lines, evidence of the formalin fixation process on protein are suggested by loadings within figure 4(a) in regions attributable to vibrations of phenylalanine residues $\left(999-1007 \mathrm{~cm}^{-1}\right)$, phenyl ring stretching and C-H bending vibrations in tyrosine $\left(1102-1200 \mathrm{~cm}^{-1}\right)$. Loadings to the overlapping Amide III $\alpha$-helical and $\mathrm{CH}$ deformation vibrational modes in protein (1345-1256 $\mathrm{cm}^{-1}$ ) are also strong. Loadings to $\mathrm{CH}$ deformation vibrations in protein, nucleic acid and lipid are also seen at $\sim 1450 \mathrm{~cm}^{-1}$ in each cell line. Loadings at $1669 \mathrm{~cm}^{-1}$ in each cell line are suggestive of adjustments to Amide I random chain and $\beta$-sheet conformations. Changes to $\mathrm{CH}$ deformation $\left(\sim 1453 \mathrm{~cm}^{-}\right.$ $\left.1,1339-1305 \mathrm{~cm}^{-1}\right),=\mathrm{C}-\mathrm{H}$ bend $\left(1284-1220 \mathrm{~cm}^{-1}\right), \mathrm{C}-\mathrm{N}, \mathrm{C}-\mathrm{C}$ and CO-O-C stretch $\left(\sim 1176 \mathrm{~cm}^{-1}\right.$ and $\left.1170 \mathrm{~cm}^{-1}\right)$ vibrations in lipid are observable throughout the PC loadings, but interestingly loadings to their phosphatidyl moieties are not. Adjustments to nucleic acids are seen as loadings to the A and B-forms of DNA (831-804 $\left.\mathrm{cm}^{-1}\right)$, osidic bond stretch $\left(1200-1102 \mathrm{~cm}^{-1}\right)$ and in-plane ring vibrations $\left(1167 \mathrm{~cm}^{-1}, 1300 \mathrm{~cm}^{-1}\right)$ and the phosphodiester stretch of the RNA backbone (831$\left.804 \mathrm{~cm}^{-1}\right)$.

Carnoy's fixative (figure 4(b)) results in spectral loadings to $\mathrm{CH}$ deformation $\left(\sim 1450 \mathrm{~cm}^{-1}\right.$ and $\left.1339-1305 \mathrm{~cm}^{-1}\right)$, Amide I $\left(1668-1661 \mathrm{~cm}^{-1}\right)$ and Amide III (1305-1247 $\left.\mathrm{cm}^{-1}\right)$ vibrations of protein. Loadings to the vibrational modes of phenylalanine (phenyl ring stretch $\left(\sim 1167 \mathrm{~cm}^{-1}\right)$, ring breathing $\left(1004-1002 \mathrm{~cm}^{-1}\right)$, $\mathrm{CH}$ in plane bend (1033-1031 $\left.\mathrm{cm}^{-1}\right)$ ), tryptophan (ring breathing at $760 \mathrm{~cm}^{-1}$ ), and tyrosine $\left(\mathrm{CH}\right.$ bend $\left.\left(1176 \mathrm{~cm}^{-1}\right)\right)$ in protein are observable. Loadings to the overlapping $\mathrm{CH}$ deformation modes in lipid $\left(1447-1453 \mathrm{~cm}^{-1}, \sim 1300 \mathrm{~cm}^{-1}\right.$ and $=\mathrm{C}$ $\mathrm{H}$ bend from $\left.\sim 1339-1247 \mathrm{~cm}^{-1}\right)$, to their $\mathrm{C}-\mathrm{N}\left(1176 \mathrm{~cm}^{-1}\right), \mathrm{C}-\mathrm{C}(1176$ and $1065-$ $\left.1062 \mathrm{~cm}^{-1}\right)$, CO-O-C $\left(1070 \mathrm{~cm}^{-1}\right)$ and C-O-P $\left(1045 \mathrm{~cm}^{-1}\right)$ moieties are present. Evidence of the effect of this fixative on nucleic acid is seen in loadings to the vibrations of the DNA backbone (928 and $898-895 \mathrm{~cm}^{-1}$ ) and the phosphodiester stretching vibrations in DNA (1095-1060 and $\left.788 \mathrm{~cm}^{-1}\right)$ and RNA $\left(811 \mathrm{~cm}^{-1}\right)$. There are also loadings to the A, B and C forms of DNA, $\left(840-788 \mathrm{~cm}^{-1}\right.$ and 870 $\mathrm{cm}^{-1}$ respectively) and to the vibrations of the ring breathing modes of the nucleic acid bases of DNA and RNA (from 788-670 $\mathrm{cm}^{-1}$ ). Adjustments to osidic moieties in carbohydrate are also suggested by loadings from 1160 to $1102 \mathrm{~cm}^{-1}$.

The effects of fixation in Meth-Ac are broadly similar to those resulting from fixation in Carnoy's fixative by virtue of the position of their PC loadings. Some important differences in the mechanism of Meth-Ac as compared to Carnoy's fixative are suggested by loadings in figure 4(c) to the phosphate moieties in lipid $\left(1085-1084 \mathrm{~cm}^{-1}\right)$ and to the glycosidic bonds in carbohydrate $\left(937-930 \mathrm{~cm}^{-1}\right)$.

Scatter plots of the PC scores are shown in figures 5(a) through 5(c). The percentage labels on each of the axes detail the amount of variance described in that PC, and demonstrate that the first three PC's describe most of the variance in the spectra. However, the spectral loadings are complex and do not easily allow identification of differences between the fixation mechanism in each cell line as a result of treatment by each fixative. The results of k-means cluster analysis are presented in Table 1. This shows the Euclidean distances between the centroids of the live cell and the fixed cell clusters, subdivided by spectral region. The position of each centroid has been established by k-means cluster analysis of the spectra in each spectral region for each cell line. This data demonstrates that, overall, formalin preserves each of the major biochemical components of the cell in a 
form that is closest to that in the live cell. The dependence of fixation mechanism on cell line and fixative is suggested by the superior effectiveness of Meth-Ac in preserving lipid in A549 cells, and in Carnoy's fixative in preserving protein in BEAS2B cells, although the comparative differences between these fixatives and formalin in both cases is slight [10].

The data in table 2 shows the mean Mahalanobis distance between the scores in the first three principal components of the live cell spectra versus the fixed cell spectra, where the PC scores are calculated on the complete spectrum. In general, this demonstrates that cells fixed in formalin correlate best to the live cell spectra. However there is a variation in overall fixation effect and the within-cluster spectral variance with cell line (with Meth-Ac apparently producing spectra more similar to the live cell than formalin in A549 cells, although with a substantial increase in the within-cluster variance). This effect in the only cancerous cell line used in this study may be due to better fixation of nucleic acid and lipid structures in the cell (which is suggested by the corresponding data in table 1). Differences in fixation between normal and cancerous tissue have previously been observed spectroscopically [7].

\begin{tabular}{c|c|c|c}
\hline Fixative (and feature) & A549 & BEAS2B & HaCaT \\
\hline Nucleic Acid & & & \\
Formalin & 0.046 & 0.060 & 0.046 \\
Carnoy & 0.071 & 0.066 & 0.064 \\
Meth-Ac & 0.052 & 0.082 & 0.069 \\
\hline Protein & & & \\
Formalin & 0.056 & 0.172 & 0.061 \\
Carnoy & 0.156 & 0.128 & 0.099 \\
Meth-Ac & 0.124 & 0.188 & 0.148 \\
\hline Lipid & & & \\
Formalin & 0.045 & 0.061 & 0.045 \\
Carnoy & 0.060 & 0.065 & 0.051 \\
Meth-Ac & 0.032 & 0.072 & 0.058 \\
\hline Carbohydrate & & & \\
Formalin & 0.069 & 0.150 & 0.060 \\
Carnoy & 0.129 & 0.151 & 0.109 \\
Meth-Ac & 0.102 & 0.213 & 0.142 \\
\hline
\end{tabular}

Table 1. Euclidean distances between the centroid (established by k-means cluster analysis of spectra) of the live cell cluster and fixed cell clusters, isolating features of interest in nucleic acid, protein, lipid and carbohydrate.

\begin{tabular}{r|cc|cc|cc}
\hline Fixative & \multicolumn{2}{|c|}{ A549 } & \multicolumn{2}{c|}{ BEAS2B } & \multicolumn{2}{c}{ HaCaT } \\
& Mean & SD & Mean & SD & Mean & SD \\
\hline Formalin & 99 & 74 & 30 & 24 & 19 & 14 \\
Carnoy & 581 & 1238 & 385 & 70 & 91 & 103 \\
Meth-Ac & 36 & 2450 & 642 & 27 & 112 & 54 \\
\hline
\end{tabular}

Table 2. Mean Mahalanobis distances between the principal component scores (in the first three PC's) of the live cell clusters versus its fixed counterparts, with the associated standard deviation in each case. 


\section{Discussion}

The present study is aimed at examining the relationship between live and fixed cell spectra using Raman spectroscopy, as a means of providing insights into the effects of fixatives on the biochemical constituents of the cell. It is thought that the mechanism of fixation of protein by formalin occurs as a result of the formation of cross-linkages between the $\mathrm{NH}_{2}$ terminals of protein amino acid residues and the $\mathrm{NH}$ group of a tertiary amide using the methylene glycol component of aqueous formalin [8]. This should contribute to a decrease in the intensity of the Amide I peak in the region of $1667 \mathrm{~cm}^{-1}$ and the appearance of a peak at $1490 \mathrm{~cm}^{-1}$ signifying increased formation of the methylene bridge itself [8]. In each of cell lines studied here the difference spectra and PC loadings for formalin fixation do exhibit reductions in the intensity of the Amide bands, and shifts in the vibrational frequency of residue amino groups of protein. This overall does imply that some denaturation of protein occurs as a result of fixation in formalin, but while methylene bridge formation may occur after fixation in formalin over the time periods that are used with tissue [12], the time periods used for fixation in this study do not appear to produce this effect as the primary means of protein coagulation. This could be due to washing of the cellular samples in $\mathrm{dH}_{2} \mathrm{O}$ after fixation, which has been shown to reverse the effect of methylene bridging in protein, albeit after significantly longer washing times than employed here [26]. In addition the coefficient of diffusability of $4 \%$ formalin is approximately $1 \mathrm{~mm}$ of tissue thickness for each hour of fixation, or approximately $16.6 \mu \mathrm{m}$ per minute [12]. Typically fixation times in formalin for tissue are of the order of 2 to 24 hours, while those for cells are of the order of minutes. Therefore the fixative can penetrate the whole cell in this time. However while the penetration time is rapid, the fixation process itself is slow as the formaldehyde must dissociate from methylene glycol (the hydrated form of formalin) in order to form covalent bonds with the molecular components of the sample [11,12]. In equilibrium the reaction forming methylene glycol in formalin solutions strongly favours the hydrated form, such that methylene glycol, having penetrated the biological sample, dissociates slowly [11,12]. Adjustments to the lipid $\mathrm{CH}$ deformation, $\mathrm{C}-\mathrm{N}$ and $\mathrm{C}-\mathrm{C}$ stretch, and $\mathrm{C}=\mathrm{O}$ stretch vibrational modes in the difference spectra, and $\mathrm{PC}$ loadings which were observed in these regions, suggest that fixation in formalin adjusts the vibrational freedom of membrane lipids, possibly through a reaction of methylene glycol in acqueous formalin with unsaturated hydrocarbon chains [6]. The global effects of each of Carnoy's fixative and Meth-Ac on the vibrations of protein and lipid appear to be similar to those seen with formalin, although in general the vibrational intensities of protein bands are weaker after treatment with both fixatives (see the difference spectra in figure 3).

It has previously been shown that both Carnoy's fixative and Methacarn (which is very similar to the Meth-Ac mixture used in this work) produce quite similar effects on DNA [12], and that DNA and RNA preservation is superior in both fixatives in comparison with formalin [12-14]. These fixatives also dehydrate the cell and cause non-specific binding of protein onto the cellular protein architecture, in addition to cleaving the DNA and RNA ribose backbone, although the length of the sequence remaining is larger in these fixatives as compared to formalin $[13,14]$. The results of the present study confirm that these effects are 
observable spectrally, and that their overall effect on nucleic acid is to reduce the intensity of nucleic spectral vibrations generally.

Overall the k-means cluster analysis employed here suggests that fixation with formalin produces spectra that most closely resemble those of the live cell, for each of the cell lines studied. All of the fixatives produce spectral variability in the major biochemical components of the cell relative to those seen in the live cell, although the level of effect of any fixative is dependent on the cell line. Fixatives that are employed because they have a lesser effect on the integrity of one component or other of the cell for biochemical analyses still cause alterations to the spectral measurements from the cell. This fact must be considered by researchers at the experimental design phase.

\section{Conclusion}

This study has examined the effect of chemical fixation on the spectral content of various cell lines in their fixed and live forms. All fixatives were observed to effect the vibrational modes of lipid, protein, nucleic acid and carbohydrate moieties. However, there are differences in the levels of change, and in the molecular species affected. Taking into account the difference spectra and the spectral loadings and the results of k-means cluster analysis, it may be concluded that formalin fixation produces a cellular spectrum that is globally more similar to that of the live cell, and therefore best preserves cellular integrity, out of the fixatives studied. Evidence suggests that Carnoy's fixative and Meth-Ac affect the spectra of nucleic acid significantly, despite both being recommended in the literature as suitable for the preservation of such species. It must also be noted that changes to the vibrations of carbohydrates occur as a result of fixation with each of the fixatives, and therefore applications of the Raman spectroscopic method to functional analyses of the physiology of cells in-vitro that intend to focus on this region of the spectrum should avoid cell fixation where possible and utilize the live cell. The study does however demonstrate the power of vibrational spectroscopy for the detailed characterization of complex cellular processes at a molecular level.

\section{Acknowledgement}

This work was funded in part by an Enterprise Ireland International Collaboration award (and French equivalent PAI Ulysses programme). The collaboration was also conducted under the DASIM (Diagnostic Applications of Synchrotron Infrared Microscopy) Special Support Activity funded by EU Contract Number 005326 under the European Union Framework 6. 


\section{References}

[1] F.M. Lyng, E.O. Faolain, J. Conroy, A.D. Meade, P. Knief, B. Duffy, M.B. Hunter, J.M. Byrne, P. Kelehan and H.J. Byrne (2007) Vibrational spectroscopy for cervical cancer pathology, from biochemical analysis to diagnostic tool. Exp Mol Pathol 82:121-129.

[2] C. Matthaus, S. Boydston-White, M. Miljkovic, M. Romeo and M. Diem (2006) Raman and infrared microspectral imaging of mitotic cells. Appl Spectrosc 60:1-8.

[3] C. Krafft, T. Knetschke, R.H. Funk and R. Salzer (2006) Studies on stress-induced changes at the subcellular level by Raman microspectroscopic mapping. Anal Chem 78:4424-4429.

[4] J.T. Motz, M. Fitzmaurice, A. Miller, S.J. Gandhi, A.S. Haka, L.H. Galindo, R.R. Dasari, J.R. Kramer and M.S. Feld (2006) In vivo Raman spectral pathology of human atherosclerosis and vulnerable plaque. J Biomed Opt 11:021003.

[5] C.A. Owen, J. Selvakumaran, I. Notingher, G. Jell, L.L. Hench and M.M. Stevens (2006) In vitro toxicology evaluation of pharmaceuticals using Raman micro-spectroscopy. $\mathrm{J}$ Cell Biochem 99:178-186.

[6] E. Gazi, J. Dwyer, N.P. Lockyer, J. Miyan, P. Gardner, C. Hart, M. Brown and N.W. Clarke (2005) Fixation protocols for subcellular imaging by synchrotron-based Fourier transform infrared microspectroscopy. Biopolymers 77:18-30.

[7] Z. Huang, A. McWilliams, S. Lam, J. English, D.I. McLean, H. Lui and H. Zeng (2003) Effect of formalin fixation on the near-infrared Raman spectroscopy of normal and cancerous human bronchial tissues. Int J Oncol 23:649-655.

[8] E. O Faolain, M.B. Hunter, J.M. Byrne, P. Kelehan, M. McNamara, H.J. Byrne and F.M. Lyng (2005) A study examining the effects of tissue processing on human tissue sections using vibrational spectroscopy. Vibrational Spectroscopy 38:121-127.

[9] G. Hastings, R. Wang, P. Krug, D. Katz and J. Hilliard (2008) Infrared microscopy for the study of biological cell monolayers. I. Spectral effects of acetone and formalin fixation. Biopolymers 89:921-930.

[10] M.M. Mariani, P. Lampen, J. Popp, B.R. Wood and V. Deckert (2009) Impact of fixation on in vitro cell culture lines monitored with Raman spectroscopy. Analyst 134:11541161.

[11] C.H. Fox, F.B. Johnson, J. Whiting and P.P. Roller (1985) Formaldehyde fixation. J Histochem Cytochem 33:845-853.

[12] M. Srinivasan, D. Sedmak and S. Jewell (2002) Effect of fixatives and tissue processing on the content and integrity of nucleic acids. Am J Pathol 161:1961-1971.

[13] M.L. Cox, S.M. Eddy, Z.S. Stewart, M.R. Kennel, M.Z. Man, J.D. Paulauskis and R.W. Dunstan (2008) Investigating fixative-induced changes in RNA quality and utility by microarray analysis. Exp Mol Pathol 84:156-172.

[14] M.L. Cox, C.L. Schray, C.N. Luster, Z.S. Stewart, P.J. Korytko, M.K. KN, J.D. Paulauskis and R.W. Dunstan (2006) Assessment of fixatives, fixation, and tissue processing on morphology and RNA integrity. Exp Mol Pathol 80:183-191.

[15] N. Masuda, T. Ohnishi, S. Kawamoto, M. Monden and K. Okubo (1999) Analysis of chemical modification of RNA from formalin-fixed samples and optimization of molecular biology applications for such samples. Nucleic Acids Res 27:4436-4443.

[16] A. Ribeiro-Silva, H. Zhang and S.S. Jeffrey (2007) RNA extraction from ten year old formalin-fixed paraffin-embedded breast cancer samples: a comparison of column purification and magnetic bead-based technologies. BMC Mol Biol 8:118.

[17] J.L. Murk, G. Posthuma, A.J. Koster, H.J. Geuze, A.J. Verkleij, M.J. Kleijmeer and B.M. Humbel (2003) Influence of aldehyde fixation on the morphology of endosomes and lysosomes: quantitative analysis and electron tomography. J Microsc 212:81-90.

[18] A.S. Leong (1994) Fixation and Fixatives, in: A.E. Woods, and Ellis, R.C. (Ed.), Laboratory Histopathology: A Complete Reference, Churchill Livingstone.

[19] A.S. Leong and P.N. Gilham (1989) The effects of progressive formaldehyde fixation on the preservation of tissue antigens. Pathology 21:266-268.

[20] A. Purea and A.G. Webb (2006) Reversible and irreversible effects of chemical fixation on the NMR properties of single cells. Magn Reson Med 56:927-931. 
[21] A. Bot (1989) Raman spectroscopy of fixed rabbit and human lenses and lens slices: new potentialities. Exp Eye Res 49:161-169.

[22] M.W. Schyns, A. Huizinga, G.F. Vrensen, F.F. De Mul and J. Greve (1990)

Paraformaldehyde fixation and some characteristics of lens proteins as measured by Raman microspectroscopy. Exp Eye Res 50:331-333.

[23] M.G. Shim, L.K.S. Wong, N.E. Marcon and B.C. Wilson (1996) The effects of ex vivo handling procedures on the near-infrared Raman spectra of normal mammalian tissues. Photochem Photobiol 63:662-671.

[24] P. Boukamp, R.T. Petrussevska, D. Breitkreutz, J. Hornung, A. Markham and N.E. Fusenig (1988) Normal keratinization in a spontaneously immortalized aneuploid human keratinocyte cell line. J Cell Biol 106:761-771.

[25] A.D. Meade, F.M. Lyng, P. Knief and H.J. Byrne (2007) Growth substrate induced functional changes elucidated by FTIR and Raman spectroscopy in in-vitro cultured human keratinocytes. Anal Bioanal Chem 387:1717-1728.

[26] R.A. Shiurba, E.T. Spooner, K. Ishiguro, M. Takahashi, R. Yoshida, T.R. Wheelock, K. Imahori, A.M. Cataldo and R.A. Nixon (1998) Immunocytochemistry of formalin-fixed human brain tissues: microwave irradiation of free-floating sections. Brain Res Brain Res Protoc 2:109-119.

[27] S. Kozubek, E. Lukasova, J. Amrichova, M. Kozubek, A. Liskova and J. Slotova (2000) Influence of cell fixation on chromatin topography. Anal Biochem 282:29-38.

[28] F. Grubbs (1969) Procedures for detecting outlier observations in samples. Technometrics 11:1-21.

[29] H. Martens, Naes, T. (1994) Multivariate Calibration, John Wiley and Sons.

[30] A.A. Afifi, Clark, V. (1999) Computer Aided Multivariate Analysis, Chapman and Hall/CRC, Florida.

[31] H.G.M. Edwards and E.A. Carter (2001) Biological Applications of Raman Spectroscopy, in: H.U. Gremlich and B. Yan (Eds.), Infrared and Raman Spectroscopy of Biological Materials, Marcel Dekker, New York, pp. 421-477.

[32] C. Krafft, Knetsche, T., Siegner, A., Funk, R.H.W., Salzer, R. (2003) Mapping of cells by near infrared Raman microspectroscopy. Vibrational Spectroscopy 32:75-83.

[33] D. Naumann (2001) FT-Infrared and FT-Raman Spectroscopy in Biomedical Research, in: H.U. Gremlich and B. Yan (Eds.), Infrared and Raman Spectroscopy of Biological Materials, Marcel Dekker, New York, pp. 323-377.

[34] I. Notingher, S. Verrier, S. Haque, J.M. Polak and L.L. Hench (2003) Spectroscopic study of human lung epithelial cells (A549) in culture: living cells versus dead cells. Biopolymers 72:230-240.

[35] G.J. Puppels, H.S. Garritsen, G.M. Segers-Nolten, F.F. de Mul and J. Greve (1991) Raman microspectroscopic approach to the study of human granulocytes. Biophys J 60:1046-1056.

[36] G. Socrates (2001) Infrared and Raman Characteristic Group Frequencies - Tables and Charts, John Wiley and Sons, Chichester, England.

[37] G. Clough and C.C. Michel (1987) The effects of chemical fixation on the permeability of frog mesenteric capillaries. J Physiol 392:463-474.

[38] P. Crow, B. Barrass, C. Kendall, M. Hart-Prieto, M. Wright, R. Persad and N. Stone (2005) The use of Raman spectroscopy to differentiate between different prostatic adenocarcinoma cell lines. Br J Cancer 92:2166-2170.

[39] I.T. Jolliffe (2004) Principal Component Analysis, Springer Science and Business Media, New York. 


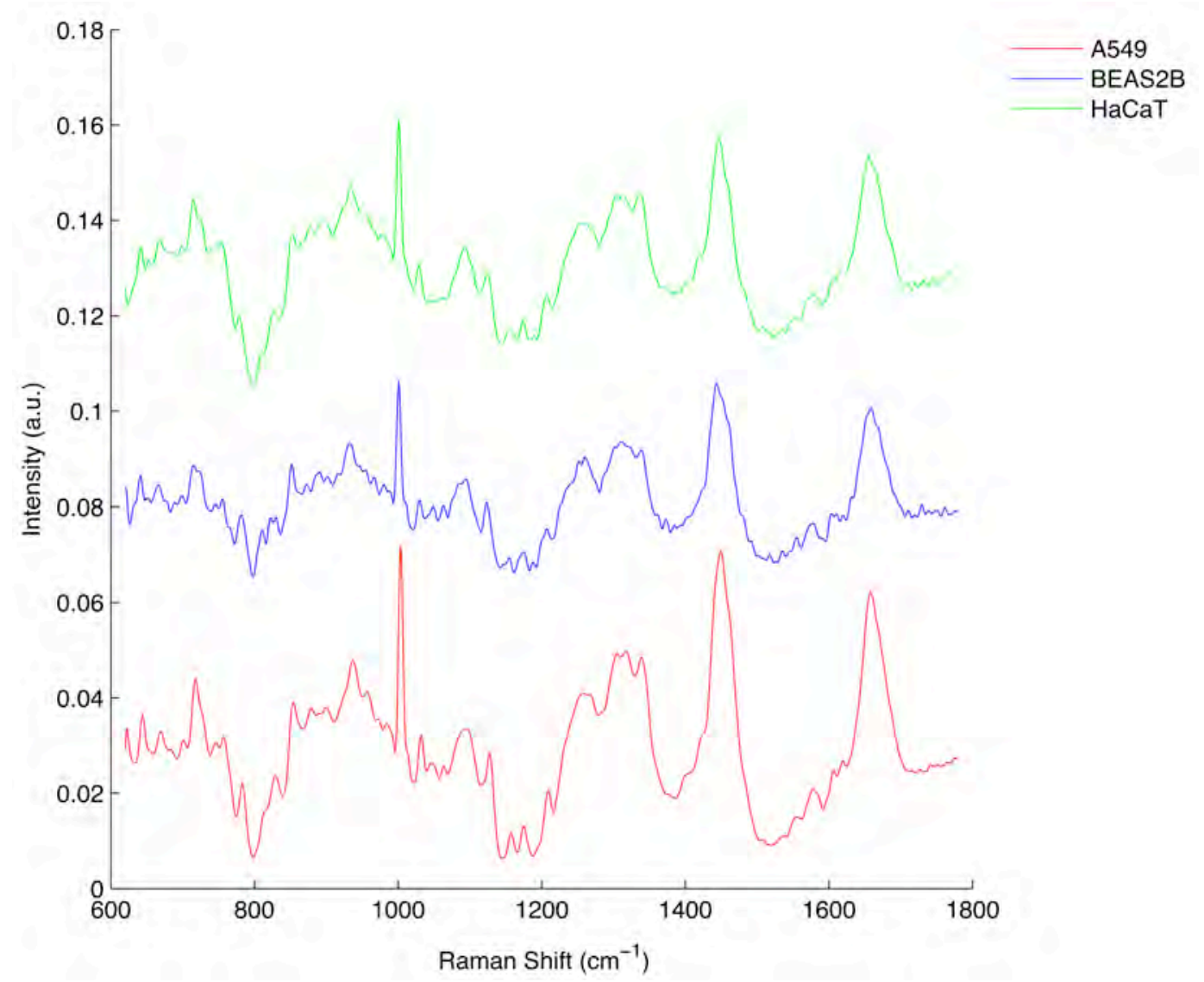

Fig. 1 Mean spectra of A549, BEAS2B and HaCaT cells in their live state. Spectra are offset manually for visual clarity. 


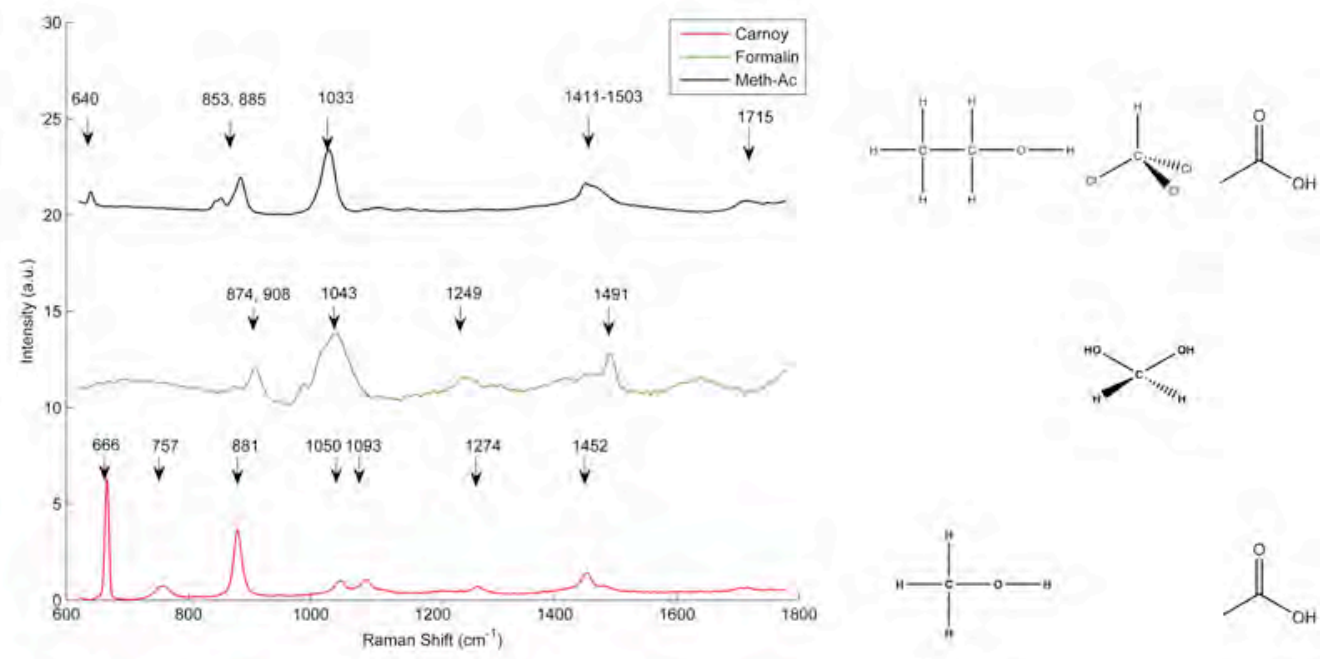

Fig. 2 Spectra of fixatives used in this study. Spectra are manually offset for visual clarity.

Molecular structures of each of the component molecules of the fixatives are given to the right of each spectrum; top (L-R): ethanol, chloroform, acetic acid; middle: aqueous formalin (methanediol); bottom: (L-R) methanol, acetic acid;

Peak assignments [36]:

(a) Carnoy's fixative: Overlap between $\mathrm{O}-\mathrm{H}$ out of plane deformation and $v \mathrm{C}-\mathrm{Cl}$ at $640 \mathrm{~cm}^{-1}$; Overlap between $\mathrm{CH}_{2}$ twist, $\mathrm{COOH}$ out of plane deformation and $v \mathrm{C}-\mathrm{Cl}$ between $853 \mathrm{~cm}^{-1}$ and $885 \mathrm{~cm}^{-1} ; v \mathrm{CCO}$ at $1033 \mathrm{~cm}^{-1} ; \mathrm{CH}_{2}$ deformation at $1411-1503 \mathrm{~cm}^{-1} ; v \mathrm{C}=\mathrm{O}$ at $1715 \mathrm{~cm}^{-1}$;

(b) Formalin: $\mathrm{CH}_{2}$ twist between $874 \mathrm{~cm}^{-1}$ and $908 \mathrm{~cm}^{-1} ; v \mathrm{C}-\mathrm{O}$ at $1043 \mathrm{~cm}^{-1}$; O-H deformation at $1249 \mathrm{~cm}^{-1} ; \mathrm{CH}_{2}$ deformation at $1491 \mathrm{~cm}^{-1}$;

(c) Methanol-glacial acetic acid: O-C-O in plane deformation at $666 \mathrm{~cm}^{-1}$; C-O deformation (carboxylic acid) at $757 \mathrm{~cm}^{-1}$; Overlap between $\mathrm{CH}_{2}$ twist, $\mathrm{O}-\mathrm{H}$ out of plane deformation (carboxylic acid) and $v$ CCO at $881 \mathrm{~cm}^{-1} ; v \mathrm{CCO}$ at $1050 \mathrm{~cm}^{-1} ; v \mathrm{C}-\mathrm{O}$ at $1093 \mathrm{~cm}^{-1}$; In plane O-H deformation at $1274 \mathrm{~cm}^{-1} ; \mathrm{CH}_{2}$ deformation at $1452 \mathrm{~cm}^{-1}$; 


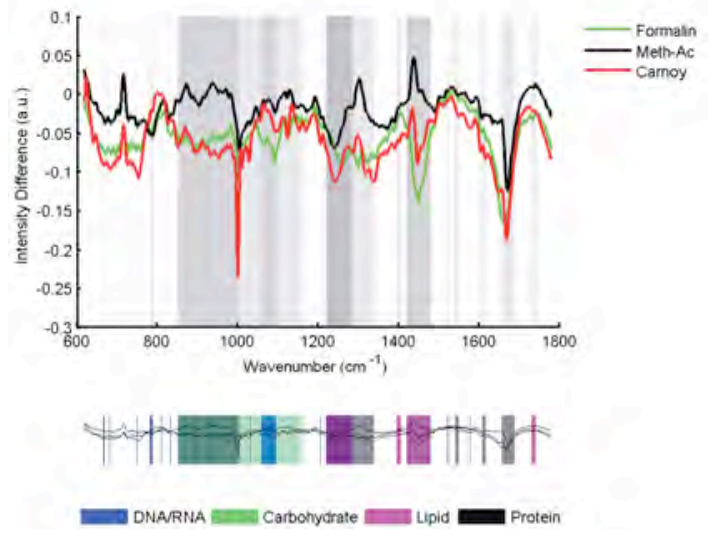

Figure 3(a)

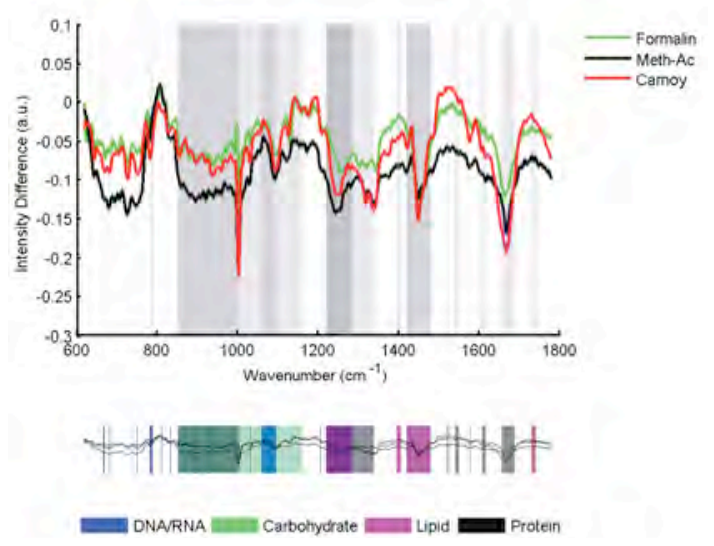

Figure 3(b)

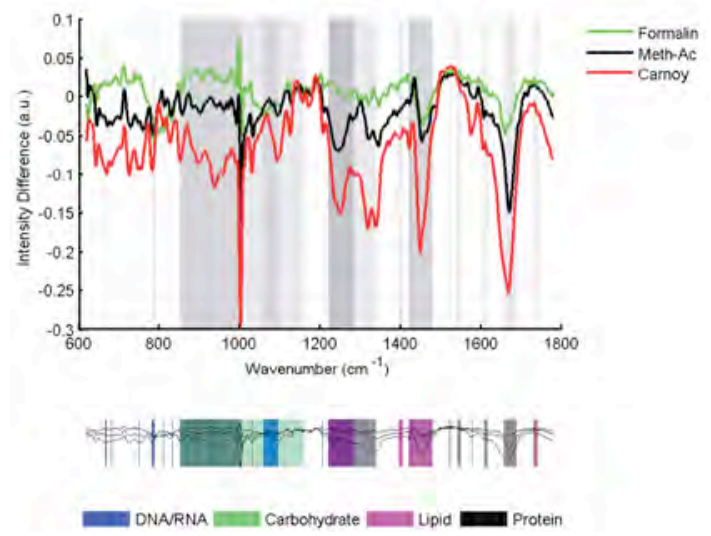

Figure 3(c)

Fig. 3 (a-c) Difference spectra of fixed 3(a) A549, 3(b) BEAS2B and 3(c) HaCaT cells fixed in Formalin, Meth-Ac and Carnoy's fixative. Calculated difference spectra are based on the mean spectra for each class and are the difference between the mean fixed cell spectrum and the mean live cell spectrum for each cell line. The width of each trace denotes the extent of the standard errors for each category. The coloured panel below each figure highlights the assignment of each spectral region with respect to its molecular category and should be used in interpreting the shaded regions in the difference spectra directly above. Regions where overlap occurs between vibrations of different moieties (e.g. CH deformation vibrations from protein and lipid between 1480 and $1420 \mathrm{~cm}^{-1}$ ) contribute to a darkening of the corresponding shaded region. 

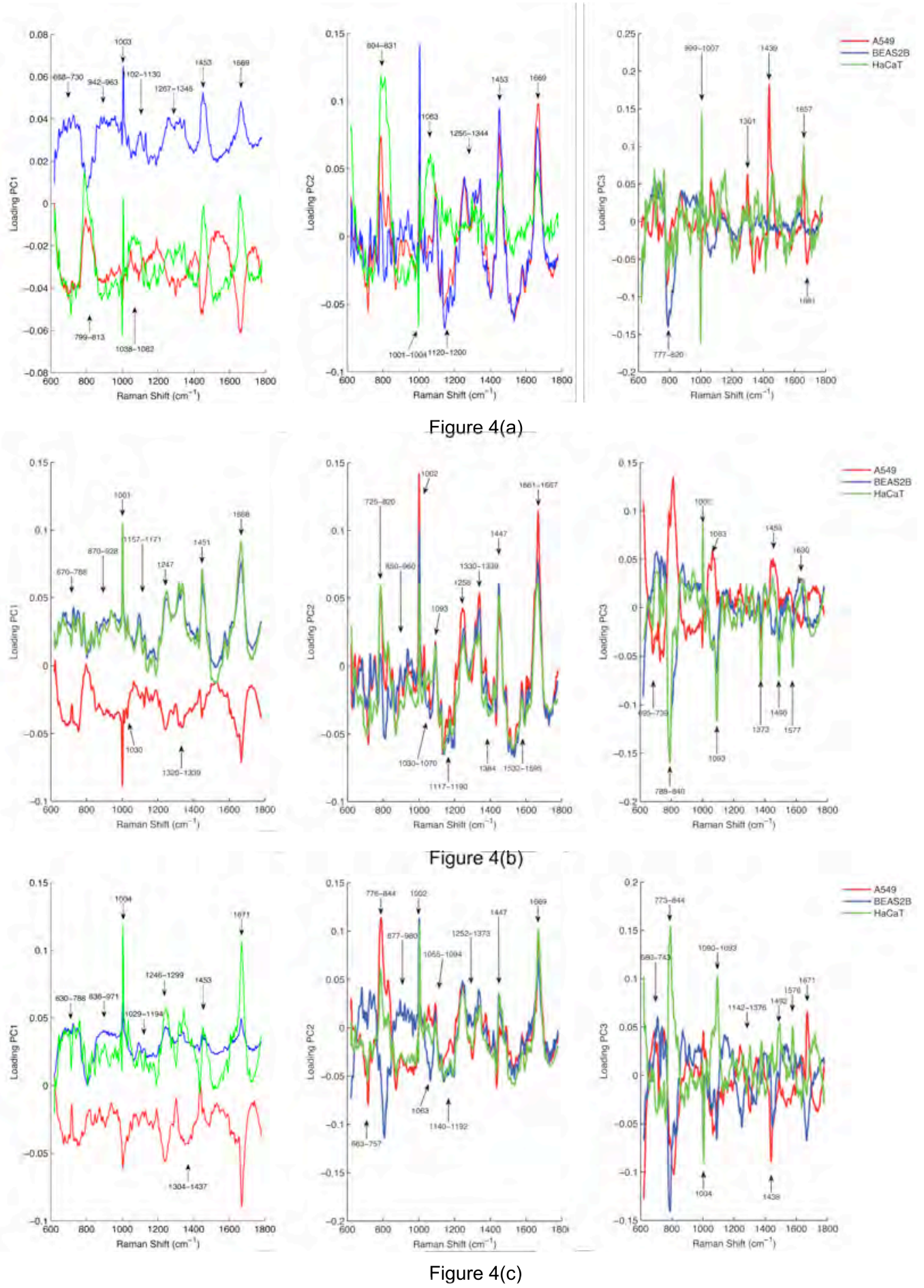

Fig. 4(a-c) PC loadings in principal component 1 through 3 for fixation with (a) Formalin, (b) Carnoy's fixative and (c) Methanol-Acetic Acid mixture. 


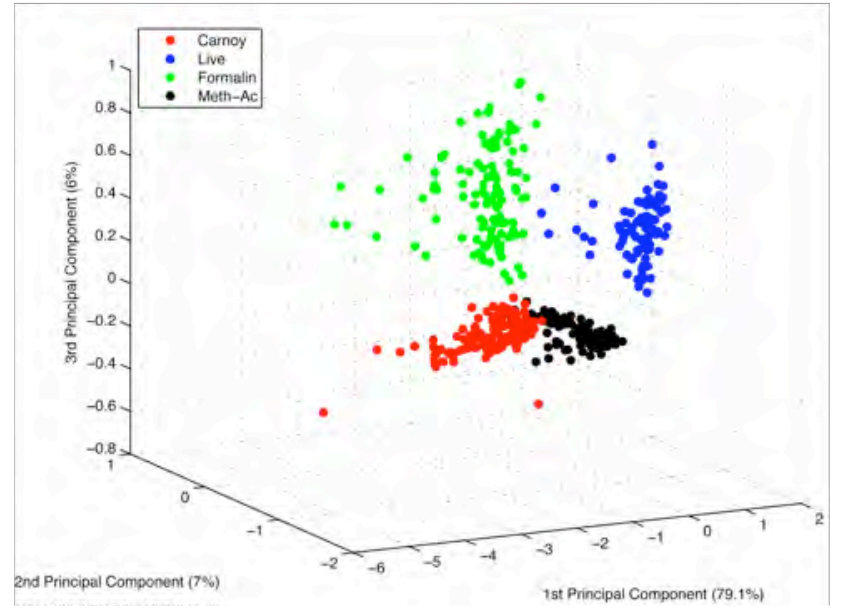

Figure 5(a)

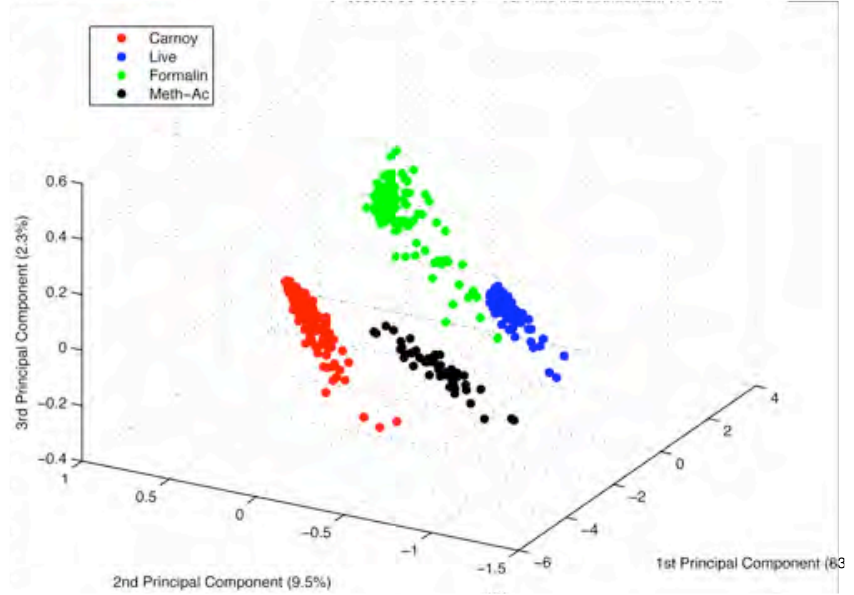

Figure 5(b)

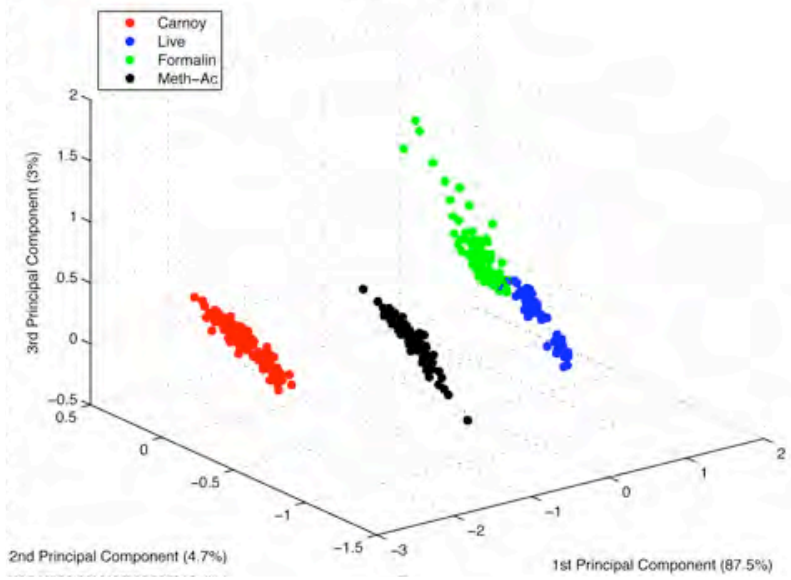

Figure 5(c)

Fig. 5 PCA score plot for (a) A549, (b) BEAS2B and (c) HaCaT Raman spectra. Percentage labels on each axis denote the variance described by that PC. There is clear separation of cellular spectra fixed with Meth-Ac and Carnoy's fixative relative to live and formalin fixed spectra. A degree of similarity between the spectral content of formalin fixed and live cell spectra is implied by the proximity of their clusters. 